\title{
Thrombus within a submitral left ventricular aneurysm: diagnosis on cross sectional echocardiography
}

\author{
Clive S Lawson, Graham E Venn, Michael M Webb-Peploe
}

\begin{abstract}
Subvalvar left ventricular aneurysms are rare and occur predominantly in black Africans. A submitral left ventricular aneurysm was diagnosed on cross sectional echocardiography in a black woman born in the United Kingdom. The left parasternal long axis view showed a highly echogenic mass apparently attached to the wall of a dilated left atrium, but the apical twochamber view showed that this was thrombus in the apex of a left ventricular aneurysm. The patient subsequently underwent surgical correction.
\end{abstract}

Subvalvar left ventricular aneurysms are rare. They occur predominantly in the black races of sub-Saharan and Western Africa with sporadic cases in North America, the West Indies, and Japan. They arise most commonly in relation to the mitral valve annulus and may contain thrombus. We report an example of a submitral aneurysm in a black woman born in the United Kingdom. To our knowledge this is only the second report of such a case in the United Kingdom and the first in which the appearance of thrombus within the aneurysm was shown by cross sectional echocardiography.

\section{Case report}

A 24 year old black woman was admitted with a two year history of dyspnoea. She was born in Britain. Her mother was also black and from Sierra Leone but the ethnic origin of her father was not known. Dyspnoea initially developed while she was visiting Sierra Leone, where rheumatic mitral valve disease was diagnosed. There was no prior history of rheumatic fever. She was treated with digoxin and diuretics with symptomatic improvement. She had stopped these five months before admission and in the month before admission progressive dyspnoea, orthopnoea, fatigue, and paroxysmal nocturnal dyspnoea had again developed.

Physical examination showed a pulse rate of 120 beats per minute in atrial fibrillation and blood pressure of $120 / 60 \mathrm{~mm} \mathrm{Hg}$. The jugular venous pressure was raised to $3 \mathrm{~cm}$ above the sternal angle. The apex beat was displaced $2 \mathrm{~cm}$ lateral to the mid-clavicular line and was hyperdynamic. A grade two pansystolic murmur was audible at the apex and radiated to the left axilla. Crackles were audible to the mid-zones of the chest bilaterally.

An electrocardiogram confirmed atrial fibrillation and showed borderline left ventricular hypertrophy but was otherwise within normal limits. A chest radiograph showed cardiomegaly with a cardiothoracic ratio of 14 / 22. There was a double right heart border with straightening of the left heart border. The lung fields showed pulmonary oedema.

Cross sectional echocardiography in the left parasternal long axis view showed a highly echogenic mass apparently attached to the wall of a dilated left atrium $(5.0 \mathrm{~cm})$. In the apical two-chamber view, however, this was identified as clot in the apex of a left ventricular aneurysm filling half its cavity (fig 1). The aneurysm arose below the posterior mitral valve leaflet and extended to compress the left atrium from behind, stretching the posterior leaflet of the mitral valve. The valve leaflets showed mild thickening and there was evidence of moderate mitral regurgitation on colour flow Doppler mapping.

The findings on cardiac catheterisation accorded with those on echocardiography, the

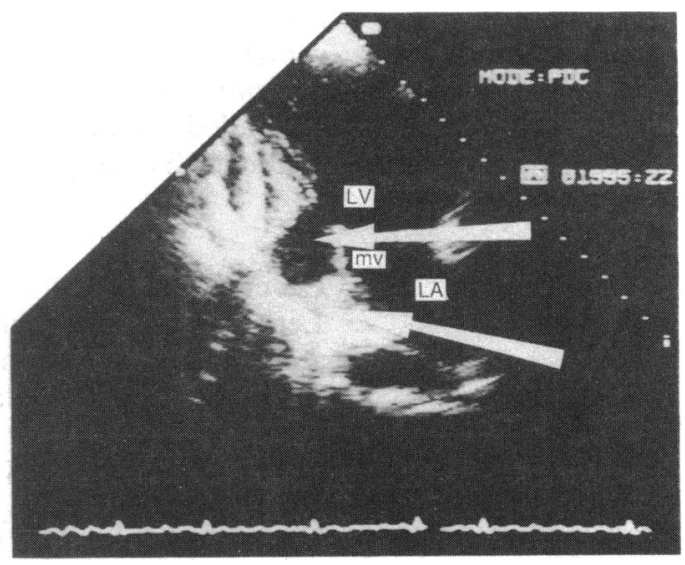

Figure 1 Cross sectional echocardiogram in the apical two-chamber view showing the aneurysm cavity (upper arrow) arising from the left ventricle immediately below the posterior mitral valve leaflet. It contained thrombus (lower arrow) and indented the left atrium. LV, left ventricle; $m v$, mitral valve; $L A$, left atrium.
Cardiovascular Research, Rayne Institute, St Thomas's Hospital Lambeth Palace Road, London SE1 7EH. 
Figure 2 Left ventricular cineangiogram in the lateral view showing the aneurysm containing thrombus which appeared as a filling defect (arrow). It arose below the left atrium which was filled by mitral valve regurgitation and was displaced superiorly. An, aneurysm. $L V$, left ventricle; $L A$ left atrium.

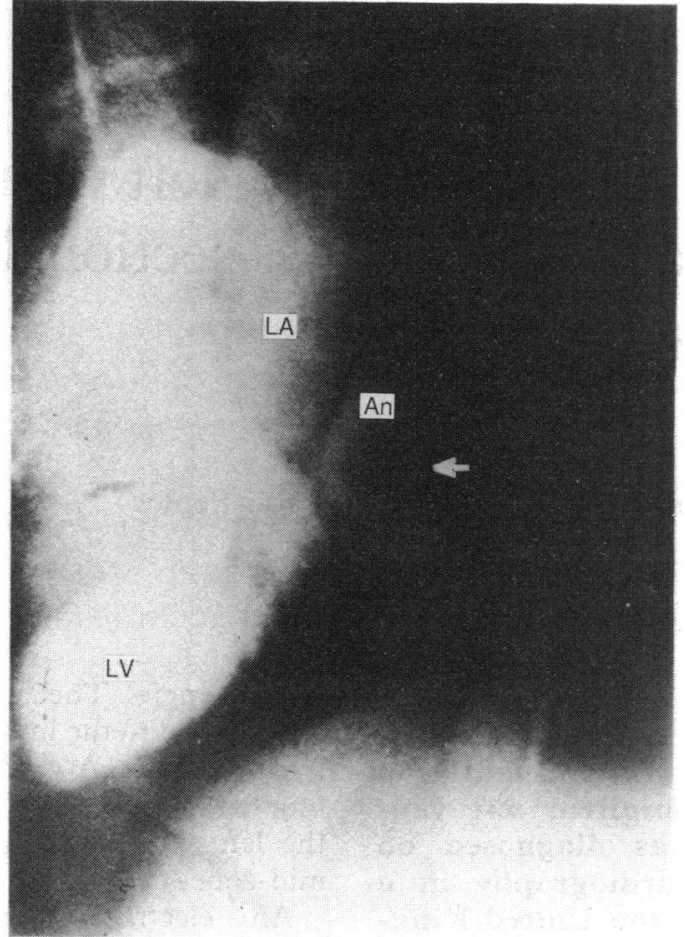

aneurysm being best defined in the lateral view. On left ventricular cineangiography two cavities filled posterior to the left ventricle (fig 2). On pulmonary artery injection with follow through the upper of these was identified as the left atrium (filling before the left ventricle) and the lower as the aneurysm (filling from the left ventricle), which contained thrombus and compressed the left atrium from below. The coronary arteries appeared normal.

She improved after treatment with digoxin and diuretics was restarted. Subsequent chest radiographs, however, showed right upper lobe infiltration and there were acid fast bacilli in her sputum. After four months of antituberculous chemotherapy she underwent successful repair of the aneurysm. The posterior leaflet of the mitral valve was extensively reconstructed and the thrombus removed.

Two months later she was readmitted with severe mitral regurgitation. At reoperation there was considerable fibrosis of the posterior leaflet and its chordal apparatus. This produced retraction of the leaflet into the left ventricular cavity and relative prolapse of the anterior leaflet. The rigidity of the annulus precluded further repair and a xenograft was inserted. She has subsequently been well.

\section{Discussion}

Left ventricular aneurysms in white patients are almost invariably associated with coronary artery disease; however, a peculiar form that is both morphologically and aetiologically different occurs in black patients. These differences were first recognised in South Africans by Jacobs and Elliott. ${ }^{1}$ They noted that whereas coronary artery disease was present in all of 57 consecutive patients of European descent with left ventricular aneurysms it was absent in $\mathbf{1 5}$ consecutive patients from Bantu tribes. They also noted that the posterior wall was the most common site of the aneurysm in those of Bantu origin. Subsequently, Abrahams et al described the association with the mitral and aortic valve rings, the former being the more common. ${ }^{2}$ Patients have since been described with aneurysms arising at the left ventricular apex. The cause of this condition remains obscure though a congenital weakness in the ventricular wall seems most likely.

Most cases occur in sub-Saharan Africa but even there this condition is rare with an incidence of $0.02 \%$ in Zaire, the source of the largest number of reports. ${ }^{3}$ The only case previously reported in this country was in a white patient; however, he had electrocardiographic changes suggestive of previous posterior infarction and his coronary arteries were not studied. ${ }^{4}$

Submitral aneurysms may be single or multiple and may extend, as here, superiorly to distort the left atrium or inferiorly into the ventricular wall or septum. They may communicate with the left ventricle via single or multiple communications and may contain thrombus. We know of no other case where thrombus within a submitral aneurysm has been discovered on echocardiography. Patients may present with emboli but the relatively narrow neck of the aneurysm makes this uncommon, unlike aneurysms associated with coronary artery disease. ${ }^{5}$

Most patients present, as here, in heart failure which may be acute or chronic. Mitral regurgitation is present in up to $68 \%$ of cases. ${ }^{6}$ Apical systolic and diastolic murmurs caused by blood flow into and out of the aneurysm via its narrow neck and indistinguishable from those of mitral valve disease have been described. There was no turbulent flow within the aneurysm on colour flow Doppler mapping in our patient. Other patients may present with chest pain (attributed to either coronary artery compression or pericardial inflammation) or with an abnormal chest $x$ ray.

The aneurysm is usually visible on a chest $x$ ray, most commonly as a bulge on the left cardiac border. In this case a discrete shadow was noted at the right heart border with straightening of the left heart border, mimicking a large left atrium and doubtless contributing to the initial misdiagnosis of rheumatic mitral valve disease.

Cardiac angiography has been the mainstay of diagnosis although there have been two case reports in the past decade in which the diagnosis was made on the basis of cross sectional echocardiography and the two techniques must be regarded as complementary. ${ }^{78}$ In neither case was thrombus present within the aneurysm.

This condition is strongly associated with pulmonary tuberculosis. ${ }^{9}$ It is unclear if the presence of a submitral aneurysm in some way predisposes patients to develop tuberculosis or if the association merely represents the high incidence of tuberculosis in patients from sub-Saharan Africa.

While symptom free patients have a good prognosis, those presenting in heart failure usually die within months. Sudden death has 
been recorded. Initial attempts at surgical excision were associated with a high mortality; however, the use of cardiopulmonary bypass and advances in technique have dramatically improved the safety of this procedure. ${ }^{10}$

This rare but important condition should be considered in patients of African origin in the clinical differential diagnosis of mitral valve disease and in the echocardiographic differential diagnosis of masses apparently within the left atrium.

1 Jacobs HD, Elliott GA. Cardiac ventricular aneurysm in South Africa. Acta Med Scand / suppl / 1955;306:84-95.

2 Abrahams DG, Barton CJ, Cockshott WP, Edington GM, Weaver EJM. Annular subvalvular left ventricular aneurysms. $Q J$ Med 1962;31:345-60.
3 Lintermans JP. L'anverism ventriculaire gauche chez le jeune africain: a propos de 23 cas. Arch Mal Coeur 1972;70:129-34.

4 Pocock WA, Cockshott WP, Ball PJA, Steiner RE. Left ventricular aneurysms of uncertain aetiology. Br Heart $J$ 1965;27:184-92.

5 Chesler E, Tucker RKB, Barlow JB. Subvalvular and apical left ventricular aneurysms in the Bantu as a source of systemic emboli. Circulation 1967;35:1156-62.

6 Kanarek KS, Bloom KR, Lakier JB, et al. Clinical aspects of submitral left ventricular aneurysms. S Afr Med J 1973;47:1225-9.

7 Davis MD, Caspi A, Lewis BS, et al. Two-dimensional echocardiographic features of sub-mitral left ventricular echocardiographic features of sub-mitral
aneurysm. Am Heart $J$ 1982;103:289-90.

8 Gupta SR, Gupta SK, Reddy KN, et al. Subvalvular aneurysm; two dimensional echocardiographic features. $J p n$ Heart $J$ 1988;29:747-51.

9 Beheyt P, Joris H. L'anevrisme ventriculaire, d'origine tuberculeuse, chez le jeune africains: etude de 3 cas. Acta Cardiol 1963;18:113-42.

10 Antunes MJ. Submitral left ventricular aneurysms: correction by a new transatrial approach. $J$ Thorac Cardiovasc Surg 1987;94:241-5.

\section{PLANTS IN CARDIOLOGY}

for winter feed. In 1922 a new and mysterious

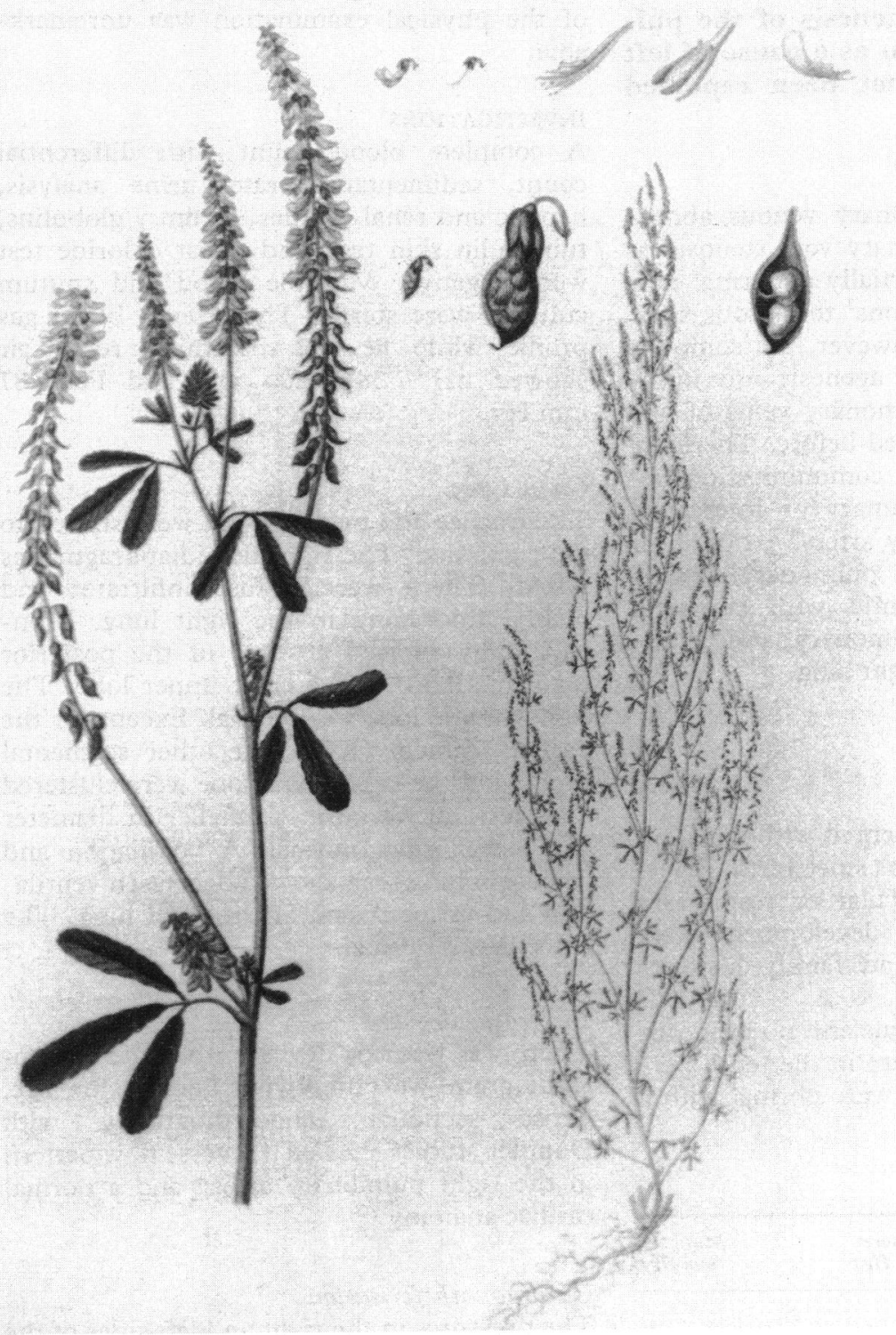

Melilotus officinalis (L.) Lam. Flora Danicae 1787: volume vi; plate 934.

Dicoumarol and warfarin

The poor soil, low rainfall, and hard winters of the North American prairies made it difficult to grow crops for animal feed until the melilots or sweet clovers, Melilotus alba and $M$ officinalis (Leguminosae), were introduced from Europe early this century. They did well and were used disease of cattle was reported in Alberta by a veterinary surgeon $\mathrm{F} S$ Schofield who noted that cattle fed on mouldy sweet clover hay were dying of haemorrhage. Properly cured hay was harmless. Schofield found that the clotting time was prolonged: a few years later L M Roderick a veterinary surgeon in Dakota showed that this was due to a reduced crude prothrombin fraction in the blood. The coincidental introduction by $\operatorname{Dr}$ A J Quick of his one stage prothrombin method proved essential for further progress. Dr K P Link, who worked in Wisconsin where the disease was common, then took up the search for the enigmatic "haemorrhagic agent". It was six years before the agent was isolated in his laboratory by $\mathrm{H} \mathrm{A}$ Campbell at dawn on 28 June 1939. It was shown to be a derivative of coumarin-the substance that gives a sweet smell to new mown hay-and was named bishydroxycoumarin. It is formed by fungal action in mouldy sweet clover by oxidation of coumarin to 4-hydroxycoumarin which is then coupled with formaldehyde. On 1 April 1940 it was synthesised. It was first used clinically as an oral anticogulant at the Mayo Clinic in 1941. The American trade name was dicumarol; and this was adapted in Britain to become the official name dicoumarol.

Link got tuberculosis in 1945 and, having unsuccessfully tried out dicumarol as a rat poison in 1942, he spent six months in the sanatorium reading about the history of rodent control. From 1946 to 1948 his laboratory staff reappraised the synthetic coumarin derivatives that they had made and found that number 42 had a potent and uniform anticoagulant action. Link proposed it as the ideal rodenticide and coined its name warfarin from the Wisconsin Alumni Research Foundation, which had promoted its use, plus the suffix from coumarin (Circulation 1959;19:97-107). Though dicumarol was enthusiastically used by clinicians warfarin, a rat poison, was ignored-until an army recruit failed to commit suicide after taking a huge dose. Warfarin was soon shown to be better and safer than dicumarol. It was introduced into clinical practice in 1954.

A HOLLMAN 